\title{
Two different faces of Cavafy in English: A corpus-assisted approach to translational stylistics
}

\author{
IRAKLIS PANTOPOULOS \\ Ionian University
}

Received: 29 January 2012 / Accepted: 13 April 2012

\begin{abstract}
A translator is seen to leave a personal mark on the text through their stylistic choices and the patterns formed by these choices. This article comprises a case study that uses a specialized comparative corpus containing translations of C.P. Cavafy's canon in order to explore the distinctive stylistic features of Rae Dalven and of Edmund Keeley and Philip Sherrard (working in collaboration), in both quantitative and qualitative terms. Exploring the different approaches to Cavafy's poetry on the stylistic level reveals the stylistic fragmentation of the poet after crossing over into a dominant language and literary market.

Overall word frequencies for each translation are examined, the stylistic features that are prominent in each case are identified, and their significance is considered. Special attention is also paid to the way a stylistic feature belonging to the 'universal aspects of literature' is treated by each translator. By foregrounding the translators and their distinct choices, the "homogenization" effects that often characterize translation into a major language are arrested. Instead, the focus falls on the factors that shape each translator's use of language and their impact.
\end{abstract}

\section{KEYWORDS:}

Literature, translation, corpus stylistics, mind-style, Cavafy, universal stylistic features, word statistics.

\section{RESUMEN}

El traductor deja una marca personal en el texto a través de sus elecciones estilísticas y los patrones que se forman a partir de dichas elecciones. Este artículo presenta un estudio de caso que emplea un corpus especializado comparado que contiene traducciones del canon de C.P. Cavafy para explorar las características estilísticas distintivas de Rae Dalven y Edmund Keeley and Philip Sherrard (en colaboración), en términos cuantitativos y cualitativos. El análisis de los diferentes enfoques a la poesía de Cavafy a nivel estilístico revela la fragmentación del estilo del poeta tras adoptar una lengua dominante y el mercado literario.

Se han examinado las frecuencias léxicas totales de cada traducción, se han identificado las características estilísticas principales en cada caso, y se ha considerado su importancia. También se ha observado el tratamiento que cada traductor da a una característica estilística considerada un "aspecto universal de la literatura". Destacando la labor de los traductores y sus distintas elecciones, se neutralizan los efectos de "homogeneización" que a menudo caracterizan a la traducción a una lengua mayor. En vez de ello, la atención se centra en los factores que dan forma al uso que cada traductor hace del lenguaje y el impacto causado.

\section{PALABRAS CLAVE:}

Literatura, traducción, estilística de corpus, visión personal del mundo, Cavafy, características estilísticas universales, recuento de palabra

\footnotetext{
*Address for correspondence: Iraklis Pantopoulos. Department of Foreign Languages, Translation and Interpreting. Megaro Kapodistria, 49100, Corfu, Greece. Tel: 003026610 87221; Fax: 00302661022293 ; E-mail: i.pantopoulos@dflti.ionio.gr
} 


\section{THE CURIOUS CASE OF C.P. CAVAFY}

Nowadays, at the second decade of the 21 st century and at a time when the flourish in interest in modern Greece along with its cultural and literary output has been largely replaced by indifference or even skepticism, the figure of the Alexandrian poet C.P. Cavafy remains aloof of these developments. Indeed, if anything, the Anglophone world's interest in Cavafy is reinforced through new translations and new readings (see below). Cavafy (1863-1933) was dead before the rise in interest in modern Greek literature in the late 20th century, and even before his own work had attained any widespread recognition outside of Greece. And yet, he constitutes one of the finest examples of a poet who worked in a language and a literature of lesser diffusion, as is modern Greek, and achieved major status in terms of impact, influence and recognition by peers and scholars alike. In terms of the translation of his work into English, he is the only modern Greek writer who has had their entire oeuvre translated by more than two different translators.

The availability of multiple published translations of the same work is more or less characteristic of literary translation. In the case of Cavafy there are now eleven different translations of the 154 poems that constitute his canon published in English since John Mavrogordato's first translation came out in 1951. The latest among these are given in the next section. Altogether, they cover a time-span of over 60 years and are both an indication and an affirmation of Cavafy's status in the Anglophone world.

This distinct property of literary translation is of course more likely to be encountered in a work that is translated from a dominant culture into a minor one and/or from a language of greater to one of lesser diffusion. The case of Cavafy is, then, remarkable in terms of both his resistance to the aforementioned overall decline in interest in Modern Greek literature, and as an instance when a work of a minor literature is the subject of multiple translations over a long period of time. This offers ideal ground for the investigation of the interface between the two literatures through the studying of the distinctive and distinct styles of different translations of the same source-text (ST) poems. By focusing on and comparing individual styles when translating into a dominant language such as English, one can break up the homogenizing attitude that is so often characteristic of major cultures and reveal the finer details of the dynamics involved in disseminating (literary) texts across cultural frontiers.

\section{TRANSLATOR AS THE "BROKEN MIDDLE"}

This dynamic relationship can be schematized by the two opposite ideological poles of any translation attempt from a major to a minor language or vice versa. Cronin, in attempting to establish the role of translation in intercultural communication, argues that it is located between two extremes described as "the pathology of difference" and the "pathology of universalism" (Cronin, 1998: 155). On the one hand, much of the recent literary (and also 
translational) criticism that has its foundations on post-structuralism and/or post-colonialism has been vociferously championing difference in literature and its preservation, or introduction, (cf. Venuti, 2008) in translation. And this with good reason, since for minority languages or cultures that are constantly under pressure in a globalized literary environment, difference is often connected to their very survival. However, as Cronin warns, "the rhetoric of difference can ultimately breed a conformism as stifling as the gospel of universalism" (ibid.: 156). The pathology of universalism, on the other hand, sees translation as "an obstacle to, not an agent of, intercultural communication" (ibid.) since it advocates a notion of the "universal" as "uniform". From this point of view difference is "demonized" and considered redundant or even dangerous for true communication.

This can be seen as typical of the modern-day outlook on translation as a 'service'. In a globalized environment where everything is translatable into information or 'data', there is increasing pressure for a translation that is "transparent" and "fluid" as a means of communicating this information. Thus, seen in practical terms, the "pathology of universalism" that Cronin describes is reflected in this "homogenizing" overhaul that seems to be advocated (and in many cases enforced) by global modernity. Naturally, this overall "globalization-as-homogenization" (ibid.) perspective can have detrimental effects for translation on the practical and theoretical levels alike. On the theoretical level it threatens to displace translation, which Boase-Beier (2006: 19) and Tabakowska (1993: 4) locate at the point of interaction between the universal and the individual, while in practical terms, by striving for an "instantaneous transparency" that replaces interaction with unidirectional reflection, it distorts both source and target.

Overall, it can be claimed that other areas of translation feel this pressure more than literary translation. However, there is no doubt that the effects of a global literary market have also changed the way in which literature is translated. This is especially true of English, a language that, because of its dominant current position (and its colonial past), makes it all the easier to create and maintain an "illusion of universalism". From the point of view of the researcher in translation, dispelling this illusion is essential in order to focus on a more balanced outlook and on a more fruitful notion of the 'universal' in relation to translation. Placing style at the centre of attention and considering it in relation to translation, not in a narrow manner, but in an open, inclusive way, can provide such a framework for productively exploring the interaction between 'universalism' and 'difference'. The way this interaction manifests in each individual translator's work offers insight into the personal, as well as cultural, context that helps shape the translators' choices and, therefore, insight into some of the factors at play when translating into a dominant language and the impact of these factors in practice.

In considering closely Wales' broad definition of style as "the perceived distinctive manner of expression" (Wales, 2001: 371), Boase-Beier (2006: 51) identifies that it is the 
choice exercised by a writer that underlies this distinctiveness, a view also central to the perspectives on style of other writers such as Enkvist (1973) and Leech and Short (1981: 1012). So, for any writer/translator, style is the result and the domain of choice. It follows that in order to systematically examine the style of a text these choices need to be accounted for.

The main aim of the study presented here is to search for those patterns in the stylistic features used by the translators which manifest their individual and distinctive identity. Consequently, the direct comparison between different translations of the same ST, rather than a comparison between ST and target-text (TT), lies at the heart of the study, with the ST forming the common 'template' on which they were based ${ }^{1}$. Stockwell (2003: 28) uses the concept of mind-style "as a means of categorizing the particular way in which an author tends to write". Examining two different target versions of a single ST mind-style makes the distinctive features of each translator's style more salient and easier to analyze.

Contemplating translation as triangulation, in the manner suggested by Cronin (1998: 155 ) -lying between the "pathology of universalism" and the "pathology of difference"- and especially regarding it as the "broken middle" that "prevents a violent and dogmatic synthesis of [these] binary opposites" (ibid.) relates it directly to style as choice and the way it is shaped by individual and social context. Munday (2007a: 8) also notes the influence exerted on translators by their "background" and adds that "[t]he language of particular textual instances is also moulded from particular circumstances that exert ideological pressure on the text as it is transferred into the target culture". Elsewhere he states that it "will have unconscious as well as conscious aspects" (2007b: 213) a fact also picked up in the typologies for style proposed by Baker (2000) and Saldanha (2005).

In a study such as this, however, distinguishing between "conscious" choices and "unconscious" habits can often be problematic and, in any case, falls more within the domain of translation process studies. Fowler (1977) who first uses the term mind-style describes it as "the distinctive linguistic presentation of a distinctive mental self" (ibid.: 103). It is precisely these distinct linguistic manifestations, as individual refractions of a single ST mind-style, those examined in this study of two different translations of Cavafy's canon.

\section{METHODOLOGY: CORPUS TRANSLATIONAL STYLISTICS}

This outlook, then, inevitably brings the writer (of originals or translations) centrally into the picture and calls for an approach that looks not only at the textual manifestation of stylistic choices, but also, crucially, at the context behind and beyond them. The limited attention that has been paid to the analysis of the stylistic features which distinguish an individual literary translator's work from that of another is here noteworthy, even though some recent studies have emerged in this direction (Saldanha, 2005; Bosseaux, 2007). 
A corpus-based methodology is used for the identification and exploration of stylistic patterns, using a comparable corpus of the latest versions of Cavafy translations by Dalven (1961) and Keeley and Sherrard (1992). The main purpose of the corpus is to facilitate direct comparison between the retranslations of the same poems, with the ST functioning as a common reference point. Such direct comparisons have the advantage of making the issue of ST influence on each translator directly observable, alongside their other stylistic traits. Dalven as well as Keeley and Sherrard have translated the entire canon of Cavafy's work, thus providing a comparable corpus comprising 154 poems each (and 40,000 words in total), which forms the basis of this case study.

In the attempt to capture the translators' stylistic profile, their "distinctive manner of expression", it is beyond the scope of this study to investigate every stylistic feature or pattern of features manifested. The choice was made instead to allow the process of the analysis to develop organically as much as possible. For this purpose a 'dual-layer' corpus-assisted -that is to say, a combination of corpus-driven and hypothesis-driven- approach to the data was chosen. Each is intended to complement, but also to control the other. "Universal stylistic aspects of literature" (cf. Boase-Beier, 2006) warrant special attention, since they are by definition both a manifestation of the universality of literariness that makes translation possible -and therefore free of certain systemic restrictions that often force translators' choices-, and at the same time subject to contextually influenced individual readings (and rewritings). Boase-Beier (ibid.: 14) suggests figures such as metaphor, iconicity or ambiguity as universal aspects, while a number of writers, especially in cognitive stylistics, such as Stockwell (2003: 14), regard foregrounding as the fundamental universal characteristic of literature. It is the treatment of this latter aspect (manifested through the use of parallelism) that is examined in this study.

As a rule, a corpus-driven approach is always a good starting point for stylistic studies of corpora since an overview of frequencies and overall statistics gives a good idea of the general texture of the corpus and offers "threads" for the researcher to pull so as to disentangle a translator's stylistic identity. The software used was principally the Wordsmith Tools 4.0 suite, developed by Mike Scott. The openly available program AntConc 3.2.1, developed by Lawrence Anthony, was used as a supplementary tool, since it facilitates search using regular expressions. For the parallel analysis of corpora the ParaConc program was used.

\subsection{Choice of target texts: Dalven and Keeley and Sherrard as translators of Cavafy}

Regarding the choice of translators that form the basis of this study, as has already been stressed, multiple English translations are one of Cavafy's distinguishing characteristics. It is also noteworthy that these translations have kept coming in a steady flow irrespective of the rise and fall of interest in Modern Greek poetry, with as many as seven new versions of 
Cavafy in English by -among others- Haviaras, Barnstone, Sachperoglou (all three in 2007), Sharon in 2008, and Mendelsohn in 2009 appearing within the last five years alone, along with a new translation of the complete canon by Chioles and an extensive selection by Connolly out in 2011. The present study, then, proposes and field-tests a methodological blueprint in terms of both analysis and applications, and is not a thorough stylistic analysis of Cavafy's presence in English. Emerging out of a larger project that examined a greater variety of Greek poets and translators, the decision was made to focus here on the translations by Dalven and Keeley and Sherrard for a number of reasons.

Firstly, both of their translations were (after Mavrogordato's) among the first of the complete cannon. With their first editions published over 40 years ago, both versions still remain in print, despite facing ever-increasing competition from newer translations. This temporal dimension has allowed them to gradually gain "cultural weight" as they have both been repeatedly quoted, and generally used as the means of representing Cavafy's poetry in English, a test that newer translations have yet to pass. Furthermore, there are a number of important analogies (especially between Dalven and Keeley) in the translators' backgrounds that go beyond contemporaneity. Apart from the fact that they both spent periods of their childhood in Greece, the most notable link is the academic positions that they held in literature departments of North American universities (both in the Northeast) for a large part of their lives, thus ensuring that their background puts them in the same "interpretative community" - a term used in cognitive poetics to refer to "a group who can be said to share a similar way of understanding and reading" (Stockwell, 2003: 33). Thirdly, and in contrast to many of the later translations of Cavafy, both Dalven and Keeley and Sherrard have reworked and revised their translations considerably over time. This does not necessarily have an impact on quality, yet, in the framework of a style-oriented study, it indicates a more "settled" final product, in terms of choices and of what is generally called the translator's voice. This is especially the case for Keeley and Sherrard as is further illustrated in the section bellow.

Finally, this decision also serves a methodological purpose, as the selection of only two translators facilitates a methodological approach that combines close-reading with corpus software analysis. This has been pointed out by such researchers in the field as Malmkjær (1998) and Baker (2000), who claim that even though word frequencies and other statistics are useful, and often greatly illuminating, starting points, they cannot be sufficient in themselves.

\subsection{A note on the Keeley and Sherrard collaboration and their stylistic identity}

Before embarking on the stylistic analysis of the translations, it is necessary to elucidate the case of the Keeley and Sherrard collaboration. Including a collaborative effort in a study that is essentially concerned with stylistic identities and their cultural implications can initially raise some questions. The Keeley and Sherrard case, however, possesses some unique features

(C) Servicio de Publicaciones. Universidad de Murcia. All rights reserved. IJES, vol. 12 (2), 2012, pp. 93-110 Print ISSN: 1578-7044; Online ISSN: 1989-6131 
that do not only qualify it, but actually make it an ideal fit for the methodology and overall outlook that this study adopts. These features have to do primarily with the manner in which Keeley and Sherrard collaborated on their translations. They never adopted a 'division of labour' approach, with each translator dealing with his own distinct share of the workload. Instead, they reworked every translation together to the point where, as Keeley admits, by the end of the final revisions he could no longer tell who had initially translated which poem (Keeley, 2000: 33, also 1983). So, for all intents and purposes, each translated poem is a manifestation of their "composite voice", as he terms it. Furthermore, they purposefully allow this composite voice to develop over time (ibid.). For Keeley and Sherrard, time, as a force of change, was an instrumental factor in translating poetry. It is precisely through the everincreasing awareness that comes with the passing of time that the voice of the translator matures (especially the composite voice of a collaborative effort). Early enough in their collaboration they came to think of their versions as neither fixed nor final and, consequently, always open to revision. So, in one sense, the course of their collaboration has been a continuous "forging" of this composite voice. Evidence of this can be mainly found in their work on Cavafy and Seferis, as successive and extensive revisions were made in both cases (for detailed examples see Keeley, 2000: 34-42).

Regarding their method of working towards this composite voice, they seem to have started with a process of exclusion rather than inclusion, meaning that, during the early stages, they did not yet have a sense of direction to go by, but had drawn up a list of things that they felt should be avoided. Among such things were any expressions that were too explicitly British or American, "archaisms, inversions, personal idiosyncrasies, and rhetorical flourishes" (Keeley, 2000: 33). It sums up the Keeley and Sherrard approach that after a collaborative career of some 35 years (the course of which entailed constant and sometimes radical revision) there are still lines in their last versions of both Cavafy and Seferis that Keeley (personal communication) admits he would revise again, if he had the chance.

\section{ONE POET, DIFFERENT STYLES: THE FACES OF CAVAFY}

\subsection{Finding a 'thread' to pull: Word statistics}

With the entire Cavafy canon available in the translations of Dalven and Keeley and Sherrard, the comparison can proceed by means of a simple quantitative analysis of basic word statistics for the two translations and gradually evolve towards greater qualitative detail. Halliday's (1971) statement regarding the usefulness of examining overall frequencies as a starting point -even as he acknowledges it is not sufficient in investigations of style- is echoed and reinforced by Baker when she notes that overall frequency "is merely a starting point, but one we cannot afford to ignore" (2004: 176). It is also in line with calls by other scholars (e.g. 
Malmkjær, 1998) for close analysis in studies of style in translation. The main advantage of the comparative model pursued here is that by keeping the variable of the ST style constant to the uttermost degree (i.e. not just different translations of the same ST author-since an author can employ different stylistic devices in different texts- but of the exact same ST) it allows for a close focus on what is prominent in each translator's style, initially on the surface level. This assertion is immediately reaffirmed by examining Table 1. In summary form, the comparative overall results show that:

- Dalven uses more running words (tokens) and more unique words (types);

- Even though both translators exhibit a very similar Type/Token Ratio (TTR) ${ }^{2}$ overall, once the figures are standardized Keeley and Sherrard manifest a notably higher ratio.

\begin{tabular}{|c|c|c|c|c|c|c|c|c|c|}
\hline & \multicolumn{2}{|c|}{ Overall Word Statistics } & \multicolumn{3}{c|}{ Lexical Words } & \multicolumn{3}{c|}{ Function Words } \\
\hline & Tokens & Types & TTR & Tokens & Types & TTR & Tokens & Types & TTR \\
\hline Dalven & 20870 & 3855 & 52.6 & 9141 & 3628 & 39.7 & 11729 & 227 & 1.94 \\
\hline $\begin{array}{c}\text { Keeley and } \\
\text { Sherrard }\end{array}$ & 19997 & 3726 & 54.8 & 9111 & 3478 & 38.2 & 10886 & 248 & 2.28 \\
\hline
\end{tabular}

Table 1. Overall, lexical words and function words statistics

Using the 'stoplist' facility of Wordsmith Tools that allows the user to define a list or words to be excluded from the results, it is possible to further investigate the initial word statistics results. Using this function makes it possible to separate the lexical (open-class) words, which are semantically charged, from the function (closed-class) words that have a mainly grammatical function ${ }^{3}$ in the work of each translator. This serves the purpose of excluding the vast majority of words that serve a purely grammatical purpose, thus allowing the easier examination of lexical words (LW). From Table 1 it becomes clear that:

- Dalven uses a greater variety of LW than Keeley and Sherrard;

- Keeley and Sherrard and Dalven's use of LW in overall numbers is balanced;

- Dalven uses more FW.

\subsection{Contractions}

Dalven, then, uses considerably more running words, without showing an accordingly higher range of vocabulary, a fact also reflected in her TTR. An attempt to see how this is manifested in the makeup of her translation, reveals a stylistic characteristic that is consistent in Dalven's work and can be connected to, and is partially accountable for, her low TTR: throughout the text she avoids using contractions and contracted forms of verbs. This is confirmed by a 
concordance search (using the Regular Expression $\left|w^{\prime}\right| w$ in AntConc) which reveals that Dalven uses the apostrophe in contracted forms of words only 49 times in the Cavafy canon, while Keeley and Sherrard use it a total of 169 times in the same poems. However, no pattern seems to emerge regarding when contracted forms were used and when not used by Dalven, so it is inconclusive to say if this is a conscious strategy on Dalven's part, or an automatic, subconscious reaction to Cavafy's particular style, as the use of contracted forms is generally associated with colloquial speech and informal writing. No safe conclusion can be reached apart from the fact that Dalven's translations of Cavafy are less colloquial in terms of overall lexical texture.

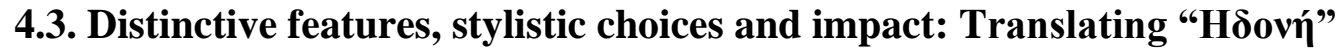

A first step beyond the initial frequencies of Table 1 is to examine the corpus for an explanation for the smaller number of LW types that Keeley and Sherrard use, even though their overall number of LW is almost identical with Dalven's. If Keeley and Sherrard had adopted a strategy of consistently rendering certain key terms of Cavafy's language, it could account for a lower TTR in LW than that of another translator who used a variety of words when rendering that same term. The term that was chosen as the focus for testing this

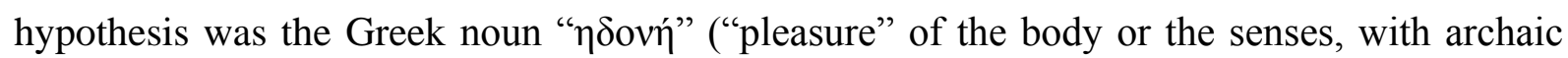
connotations). It is used widely and consistently by Cavafy and appears a total of 30 times in his canon.

It is, then, essential to look at the broader picture for each translator, by examining how they have rendered the term in throughout the Cavafy corpus, before any reasonable claims can be made. By using a combination of the Wordlist and Concordance functions it is possible to pull up the list of each translator's use of the corresponding English terms. Then any false entries, that is to say cases where "pleasure" or "delight" etc are used with a different meaning and not as a translation of " $\eta \delta o v \eta$ ", need to be manually removed and the resulting lists crosschecked against the ST. Dalven uses ten times the word "pleasure" as a direct translation of

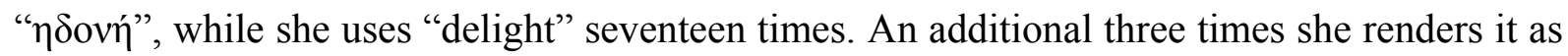
"voluptuousness". Keeley and Sherrard, on the other hand, use "pleasure" 25 times, "sensuality" three times, and "delight" twice. Immediately, these results confirm the initial hypothesis suggesting a strategy on Keeley and Sherrard's part for the consistent translation of " $\eta \delta$ ov'" as one of the key terms in Cavafy. Even though not $100 \%$ consistent, they use "pleasure" in the vast majority of instances.

\subsection{Translating universal aspects of style: Foregrounding by parallelism in Cavafy}

In relation, specifically, to the translation of poetry, foregrounding is an instrumental aspect for the translator to consider since it is directly connected to the very function of poetic texts. It is the strongest and most common mechanism an author employs in order to draw the 
readers' attention to particular structures or aspects of a poem, and, to the extent that it is possible, manipulate and influence their inferences. It is in cognitive terms a "communicative clue" (Gutt, 2000). The two most common forms of foregrounding are deviation and parallelism. Foregrounding is related to the psychological notion of figure/ground alignment (whereby, certain parts of a picture or scene are prominent and comprise the foreground (figure) while others the background (ground)). This psychological origin of the notion qualifies foregrounding as one of the cognitive based stylistic characteristics of literature that are essentially universal and therefore viable for stylistic studies of translation.

In the case of translating Cavafy, his poetry lacks many stylistic ornaments often associated with poetic language, such as metaphor or vivid imagery. Therefore, foregrounding and especially parallelism, in a sense, throw themselves up at the researcher as the distinguishing stylistic feature, since they are commonly and variedly used in the ST. Colaclides in his wide-ranging review of the linguistic structures in Cavafy and their effect, notes the significance of repetitions in his poetry which are "far from simple and connected by a number of enhancing means" (2006: 3). A characteristic example of such an instance is the last two lines of the first stanza of "In Sparta". The ST parallel structure is treated quite differently by the two translators:

\begin{tabular}{|c|c|}
\hline ST: & 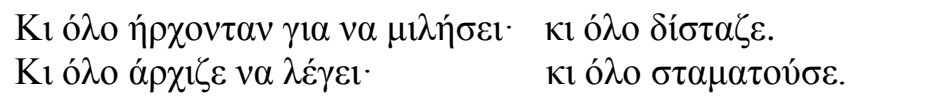 \\
\hline Dalven: & $\begin{array}{l}\text { And he was always about to speak; and he always demurred. } \\
\text { And he always started to say it; and he always faltered. }\end{array}$ \\
\hline $\begin{array}{l}\text { Keeley and } \\
\text { Sherrard: }\end{array}$ & $\begin{array}{l}\text { And he would be about to speak yet always hesitate, } \\
\text { would start to tell her yet always stop. }\end{array}$ \\
\hline
\end{tabular}

Dalven's version is much closer to the structure of the ST in both form and effect, since in this case the two are interrelated. The structural parallelism is retained, each line is divided in two by the use of a semi-colon, and each half is parallel to the one in the next line. Additionally, the two verbs in the first half of each line are synonymous. The overall effect of the parallelism, to enhance the significance of the scene, is thus retained in Dalven and the two verbs that end each line of the ST, "hesitated" and "stopped", are projected onto each other and associated etymologically in a way that is not the norm in the language. Keeley and Sherrard, on the other hand, appear to follow the structure more loosely, with only the second half of each line strictly parallel, while no punctuation is used to divide the lines. The association of the verbs is maintained, but the overall effect is somewhat weakened, to the benefit of the uninterrupted flow of the text. The effect of the parallel structure is also evident across the two different translations, as the verbs each translator uses are juxtaposed and Dalven's choices appear more dated than Keeley and Sherrard's. 


\begin{tabular}{|c|c|}
\hline \multicolumn{2}{|c|}{ ST } \\
\hline \multicolumn{2}{|c|}{ 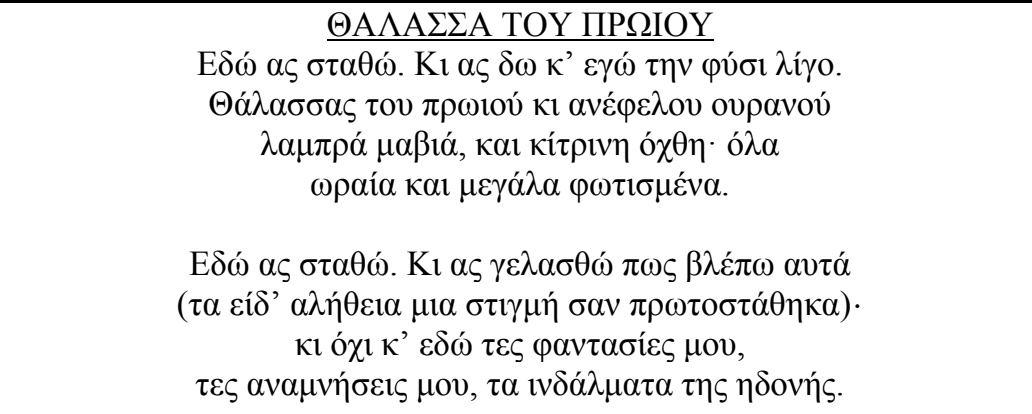 } \\
\hline Dalven & Keeley and Sherrard \\
\hline $\begin{array}{l}\text { MORNING SEA } \\
\text { Let me stand here. Let me also } \\
\text { look at nature a while. } \\
\text { The shore of the morning sea and } \\
\text { the cloudless sky } \\
\text { brilliant blue and yellow } \\
\text { all illuminated lovely and large. } \\
\text { Let me stand here. Let me delude } \\
\text { myself that I see these things } \\
\text { (I really did see them a moment } \\
\text { when I first stopped); } \\
\text { and not that here too I see my } \\
\text { fantasies, } \\
\text { my memories, my visions of } \\
\text { sensual delight. }\end{array}$ & $\begin{array}{l}\text { MORNING SEA } \\
\text { Let me stop here. Let me, too, look } \\
\text { at nature awhile. } \\
\text { The brilliant blue of the morning } \\
\text { sea, of the cloudless sky, } \\
\text { the yellow shore; all lovely, all } \\
\text { bathed in light. } \\
\text { Let me stand here. And let me } \\
\text { pretend I see all this } \\
\text { (I really did see it for a minute } \\
\text { when I first stopped) } \\
\text { and not my usual day-dreams here } \\
\text { too, } \\
\text { my memories, those images of } \\
\text { sensual pleasure. }\end{array}$ \\
\hline
\end{tabular}

Table 2. "Morning Sea"

If, then, foregrounding illustrates features that "the author, consciously or unconsciously, signals as crucial to our understanding of what he has written" (Boase-Beier, 2006), these features may be further filtered through the translator's consciousness, but, as the above examples illustrate, remain instrumental to the function of the TT. Parallelism in particular, with its evident patterning structure and function, "acts as powerful force in the cohesion of foregrounding" (ibid.), and the choices made in its translation have a decisive impact on the stylistic integrity of the TT. The poem "Morning Sea" (Table 2) offers a clear example in the parallel structure between the first lines of its two verses. Dalven, in agreement with the tendency noted in the first example, reproduces the parallelism at the beginning of the two verses with "Let me stand here. Let me..." at the start of each verse. In the first line of the poem this is followed by the verb "view", while in its parallel in the second verse by "delude (myself)". This sustains in the TT the association of the first verse with the natural world the poet observes, and of the second with his inner reflections and desires. What is not retained in Dalven's translation is the repetition of the verb form " $\sigma \tau \alpha \theta \omega$ " (stand, stop, pause) that is used in these two lines but also echoed later as " $\pi \rho \omega \tau \sigma \sigma \tau \alpha \dot{\theta} \eta \kappa \alpha "$ (first stood/stopped/paused). Dalven uses "stand" in two parallel lines, but then breaks the 
repetition pattern by using "stopped" in the last instance. The ambiguity of the original is somewhat weakened in this way.

Keeley and Sherrard, however, only use the conjunction "and" in the second verse which has the opposite effect on the TT, in effect weakening the parallel structure. Yet, their choice does not stand out for the target-language (TL) reader who might find it natural that "and" was used in the second instance in order to differentiate the first lines of each stanza, with the second following logically after the first. This sense of logical (and chronological) progression in the Keeley and Sherrard translation is further established by their choice to use "stop" for the first line on the poem, and "stand" for the second. In this way the image is established of the poet first stopping at the scene, and then standing there and observing. This is reaffirmed by their choice of "first stopped" for " $\pi \rho \omega \tau \sigma \sigma \tau \alpha \dot{\theta} \eta \kappa \alpha$ ". The parallelism and its effects are substituted for the purpose of disambiguation, and -primarily- of establishing chronological progression in the scene described by the poem.

Finally, in the poem "One Night" (Table 3, below) an intricate structure is employed first to set the scene, and then foreground certain associations between elements of the poem. It is the first verse and the first line of the second verse, which introduce the setting of the poem. In the first stanza of the poem eight adjectives are dominant, all of them with strong negative connotations, introducing a setting of decadence. Against this backdrop, two consecutive parallel constructions are used in the second part of the poem, in order to juxtapose this decadence with the "intoxicating" delight of love that took place. These two structures (marked in Table 3, the first underlined and the second in bold) are not in succession but are actually intertwined, and further reinforced by the repetition of the noun " $\mu \varepsilon \dot{\theta} \theta ”$ " (drunkenness/intoxication) a derivative of the verb " $\mu \varepsilon \theta \omega$ " (to get drunk) that closes the poem.

Dalven's translation, once more, attempts to stay as close as possible to the structure of the ST. To this end, both parallel structures are translated almost word for word. At the same time, she repeats three times the noun "lips", which in the ST is the syntactic object in the sentence, comprising the second half of the first structure, but is then implied and not mentioned in the second parallel structure. This is in fact the contact point between the two parallelisms, and Dalven's choice to repeat it, presumably for the sake of correct and clear English diction, while retaining the ST structure, strengthens the connection and reinforces the effect of the ST by adding to the foregrounding the repetition of "lips". This is also, to an extent, a compensation for the etymological foregrounding of " $\mu \varepsilon \theta \omega$ " at the end of the ST, through the repetition of its derivative " $\mu \varepsilon \dot{\theta} \theta$ " twice in the second verse. This is lost in Dalven's translation as she uses "ecstasy" twice, which has no direct etymological relation to the adjective "drunk" she uses at the end. 


\begin{tabular}{|c|c|}
\hline ST: & 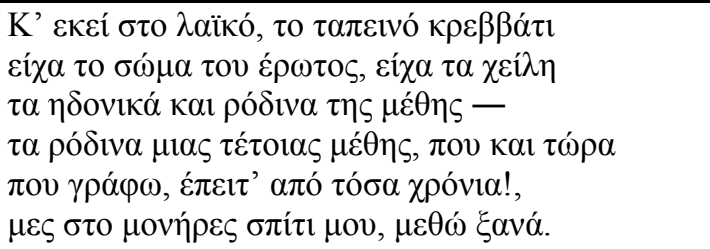 \\
\hline Dalven & $\begin{array}{l}\text { And there on the much-used, lowly bed } \\
\text { I had the body [of love,] I had the lips, } \\
\text { (the voluptuous and rosy) lips[of ecstasy- ] } \\
\text { rosy lips of (such) ecstasy, that even now } \\
\text { as I write, after so many years! } \\
\text { in my solitary house, I am drunk again. }\end{array}$ \\
\hline Keeley and Sherrard & $\begin{array}{l}\text { And there on that common, humble bed } \\
\text { I had [love's] body, had those [intoxicating ] lips, } \\
\text { (red and sensual,) } \\
\text { red lips of (such) intoxication } \\
\text { that now as I write, after so many years, } \\
\text { in my lonely house, I'm drunk with passion again. }\end{array}$ \\
\hline
\end{tabular}

Table 3. "One Night" Second stanza ${ }^{4}$

In Keeley and Sherrard's case the etymological foregrounding of " $\mu \varepsilon \theta \omega$ " is retained, if diluted, by the repetition of "intoxication" which does reinforce the noun "drunk" of the final line. The repeating effect of "intoxication" is weakened further, as they use the term once (for the second occurrence of " $\mu \varepsilon \theta \omega$ " in the ST), while they use "intoxicating" in the second line of the verse. This, inevitably, signals that their translation of the "rosy lips..." repetition is not consistent. In contrast to Dalven, Keeley and Sherrard avoid repeating "lips" three times in their translation, and, in order to achieve this, use "intoxicating" as an additional adjective, which, together with "red" and "sensual" which follow in the next line, collocate with the first occurrence of "lips". The result is a less cumbersome structure, attracting less attention to itself, as do the adjectives selected, which are plainer than those used by Dalven. Additionally, with the introduction of "red lips of such intoxication", which mirrors the preceding phrase, the foregrounding effect of the ST construction is not entirely lost. From the first parallelism of the ST verse, the repetition of the verb form ("had") is retained, but again a more prosaic structure is preferred, with the omission of the personal pronoun the second time, and the introduction of "those" before "intoxicating lips".

\section{REFRACTING MIND-STYLE}

The next step is to look beyond these initial frequencies in the work of each translator, and the stylistic choices they adopt, and search for patterns, overall tendencies, and their significance. In the limited analysis (in terms of scope) that was presented above, a number of indications emerge regarding the translators' stylistic identity. Dalven manifests a noticeable tendency to use more words than Keeley and Sherrard. Furthermore, it is determined that this is mainly 
due to her higher use of grammatical rather than lexical words. A stylistic trait that has been found to greatly contribute to this is Dalven's very limited use of contractions and contracted forms. By closely examining her treatment of parallelisms in Cavafy it is evident that Dalven is consistent in her rendering of ST structural features and attempts to stay as close to the overall ST formal structure as possible. This, however, is not the case when it comes to the way she renders certain key ST lexical terms. The way she has translated " $\eta \delta o v \eta$ ", a prominent term throughout Cavafy's work, shows that she is inconsistent in this respect. This affects the way his poetic landscape as a whole comes through in English.

Keeley and Sherrard reveal a different pattern. They allow themselves the flexibility to be consistent in the rendering of terms that define the poet's individual style by adopting a free verse rendering for their TT. They also exhibit a wider range of vocabulary in their translation, as manifested by their higher TTR, despite making use of fewer words than Dalven, overall. Their use of the same term consistently in 25 out of a total of 30 occurrences of " $\eta \delta o v \eta$ " in Cavafy's canon shows that they clearly recognize it as a key term in his poetry, while their overall strategy of using free verse throughout allows them to retain this consistency in the TT. In their text, such structural elements as parallelisms and repetitions are effectively weakened, obviously aiming for a less cumbersome text from the TL point of view, one that flows more naturally, without considerably distorting the ST sense. The effect of this choice is a TT that is 'normalized' or 'domesticated' but whose semantic content remains intact even though it is rendered in more, literally, prosaic terms. This is a pattern prevalent throughout their work and it is the accumulative result of a variety of features on the stylistic level.

Even though these initial results are not sufficient for drawing solid overall conclusions regarding the translators' stylistic identities, this study wishes to highlight the advantages and applications of such a comparative analysis. By using stylistics as a tool for clearly and systematically bringing the translators' choices into focus, and contemplating the impact of these choices on the TT, the researcher by default dispels the preconception of translation as a homogenizing process. When dealing with translations from a minor into a dominant language a stylistic approach helps illustrate the different ways in which the source can influence (and ultimately enrich) the target in terms of language and literature. Most importantly though, a comparative stylistic analysis of different translations of the same ST "cracks" the image of translation as a seamless, transparent transfer of information by bringing the translator sharply into focus as a (re-)writer of texts with his/her own stylistic fingerprint and his/her personal reading of the ST. What is more, using a corpus-assisted approach for the stylistic analysis offers both the wide scope and the precision required, and even helps diminish the risk of partiality on the part of the researcher. The Cavafy corpus used for this study consists of about 40,000 words in total, which makes it quite small in 
relation to the corpora that are available nowadays. Yet, it contains Cavafy's entire canon which means that it facilitates a thorough analysis.

What the case study undertaken here shows, is that the way the target-culture adopts a literary text written in a language of lesser diffusion is anything but straightforward and that the translation process is shaped by factors relating to each translator's individuality, in addition to their social and cultural background and to those universal aspects which make translation possible. The distinctive stylistic identity that each translator manifests constitutes in fact a different facet of the mind-style encapsulated in the ST, refracted through the individual reading of the translator into an amalgam mind-style that contains elements of both ST author and translator. Dalven's choice, for instance, not to use contractions in her translation of Cavafy is a step towards highlighting the archaic language that often characterizes the ST. Such a reading, however, is only one facet of the idiosyncratic language of Cavafy and in sharp contrast with the plain, modern, and almost prosaic idiom that is characteristic of Keeley and Sherrard's text. Consequently, stylistic choices and their potential underlying strategies can be seen as the "cracks" on the glass that refract the ST into different facets in the TL.

\section{CONCLUSIONS}

By adopting an expanded model of style in relation to translation, one that considers each translator's distinctive manner of expression as consisting of not only the linguistic manifestations of style but also their underlying patterns, and by taking into account not only the textual but also the para- and extra-textual features, the study of translation can interweave text and context into its methodological framework. Space restrictions do not allow elaboration on these aspects here, but this expanded model which is used in a study wider in scope -on which this article draws- makes use of the para-texts and extra-textual material that accompany the translations, and also draws on a detailed account of the translators' theoretical reflections, as these have been documented. This approach offers a comprehensive view of the identity of the translator as a (re-)writer and also further establishes the backdrop to his/her individual linguistically manifested choices. In a characteristic example referring to this case study, in their forewords to their translations of Cavafy, Dalven and Keeley and Sherrard describe their respective strategies in translating the poet. Keeley and Sherrard state that they have "chosen to render with repetitive consistency those words that Cavafy repeated often in establishing his particular personal landscape" (Cavafy, 1992: xvi) while Dalven simply says that "the translations are as close to the original as I could make them" (Cavafy, 1961: 222). Both these remarks, clearly reflected in their individual stylistic choices as 
analyzed above, attain even more prominence when considered against the similar cultural background -or interpretative community-shared by the translators.

Mapping different translations of the same ST onto each other, however, does not boil down to focusing on the above mentioned pathology of difference. On the contrary, a comparative stylistic analysis can be the platform for taking stock of the universal, apart from the individual, aspects in translation. On the one hand, the different TL translations of the same ST -each one presenting a different facet of the ST mind-style- are not to be regarded as mutually exclusive but rather as mutually complementing. In the limited study presented here, Dalven's cumulative stylistic choices can be claimed to reflect aspects of the pathology of difference as she stays close to the ST in terms of certain formal elements, even at the expense of lexical coherence, while Keeley and Sherrard lean towards the pathology of universalism, with their clear favouring of a less cumbersome, naturally flowing TT by "sacrificing" certain formal ST features. These, however, are clearly different points in a spectrum rather than binary opposites. In fact, when refracted in this manner, the ST is strengthened as its stylistic subtleties induce different readings/re-writings from each translator. Additionally, such a comparative analysis -but one that uses translators from different rather than similar interpretative communities - can help shed light on the habitual use of language by each translator that has its roots both in personal linguistic experience and universal human cognition. As a matter of fact, according to Hoey's (2005) "lexical priming" theory, the translator's own experiences and education, in both source- and target-language, can play an equally important part in bringing about a stylistic shift in the TT as any motivated strategy.

Cronin advocates "critical universalism" as a "celebration of difference that leads to an embrace of other differences, the universalism lying not in the eradication of the other but in sharing a common condition..." (2000: 91). The use of stylistic analysis in relation to translation is an old tool that has been commonly used in a prescriptive, ST-focused manner and is often associated with such approaches. However, it can be an extremely valuable practical tool in researching precisely this critical universalism and its implications and applications. By examining the different stylistic identities of Dalven and Keeley and Sherrard alongside each other, the focus of the study is precisely on the point where "the universal in human cognition" and "the infinite variety of products of cognitive processes" interact (Tabakowska, 1993: 4). The different facets of Cavafy that are reflected in each translator's work are the product of this interaction, and illustrate the fragmented rather than transparent nature of translation. It goes without saying, that a wide-scope corpus study of all the translations of Cavafy into English, or even a detailed examination of his English "faces" in the 21 st century, can offer invaluable ground for further research along the same lines in both range and variety.

(C) Servicio de Publicaciones. Universidad de Murcia. All rights reserved. IJES, vol. 12 (2), 2012, pp. $93-110$ Print ISSN: 1578-7044; Online ISSN: 1989-6131 


\section{NOTES}

1. It should be noted at this point, that the case study presented here is part of a project with a wider scope that also examines translations of different authors by the same translator, as well as their use of extra-textual material, in an attempt to capture the translators' complete stylistic profile.

2. A type/token ratio is typically considered as an indication of the range of vocabulary used by a writer.

3. This stoplist consisting of 320 function words (FW) was produced by Leah Gilner and Franc Morales and is available online at http://www.sequencepublishing.com.

4. In this table the two clauses of the first parallelism are underlined, in each instance and those of the second parallelism are in bold. Italics indicate each translator's choices for the ST repeated terms " $\mu \varepsilon \dot{\theta} \theta \eta$ " (intoxication) and " $\mu \varepsilon \theta \omega ́$ " (become intoxicated).

\section{REFERENCES}

Baker, M. (2000). Towards a methodology for investigating the style of a literary translator. Target, 12(2), 241-266.

Boase-Beier, J. (2006). Stylistic Approaches to Translation. Manchester: St. Jerome Publishing.

Bosseaux, C. (2007). How Does it Feel? Point of View in Translation: The Case of Virginia Woolf into French. Amsterdam and New York: Rodopi.

Cavafy, C. (1952). Poiimata [Poems)]. Athens: Ikaros.

Cavafy, C. (1952/1961). The Complete Poems of Cavafy. (R. Dalven, Trans.). New York: Harcourt.

Cavafy, C. (1952/1992). Collected Poems. (E. Keeley \& P. Sherrard, Trans.). Princeton, NJ: Princeton University Press.

Colaclides, P. (2006). To doulema tis glossas ston Kavafi [The way Cavafy works language]. In K. Meletes (Ed.), Elliniki Grammatia kai Glossa [Studies: Greek Letters and Language]. Heraklion: Heraklion Municipal Library.

Cronin, M. (1998). The cracked looking glass of servants. Translation and minority. Languages in a global age. The Translator, 4(2), 145-62.

Cronin, M. (2000). Across the Lines: Travel, Language, Translation. Cork: Cork University Press.

Dalven, R. \& Auden, W. H. (1961). The Complete Poems of Cavafy. London: Hogarth Press.

Enkvist, N. E. (1973). Linguistic Stylistics. The Hague: Mouton.

Halliday, M. A. K. (1971). Linguistic function and literary style: An inquiry into the language of William Golding's "The Inheritors". In Literary style: A symposium (pp. 330-65). London and New York: Oxford University Press.

Hoey, M. (2005). Lexical Priming: A New Theory of Words and Language. New York: Routledge.

Keeley, E. (1983). Modern Greek Poetry: Voice and Myth. Princeton: Princeton University Press.

Keeley, E. (2000). On Translation: Reflections and Conversations. London: Taylor \& Francis Ltd.

Keeley, E. \& Sherrard, P. (1992). CP Cavafy: Collected Poems. Princeton: Princeton University Press.

Leech, G. N. \& Short, M. (1981). Style in Fiction: A Linguistic Introduction to English Fictional Prose. London: Longman.

Malmkjaer, K. (1998). Love thy neighbour: Will parallel corpora endear linguists to translators? Meta: Translators' Journal, 43, 534-541.

Munday, J. (1998). A computer-assisted approach to the analysis of translation shifts. Meta: Translators' Journal, 43, 542-556.

Munday, J. (2007a). Translation and ideology: A textual approach. The Translator, 13(2), 195-217.

Munday, J. (2007b). Translation as Intervention. London: Continuum.

Saldanha, G. (2005). Style of translation: An exploration of stylistic patterns in the translations of Margaret Jull Costa and Peter Bush. Unpublished Phd Thesis. Dublin: School of Applied Language and Intercultural Studies, Dublin City University.

Stockwell, P. (2003). Cognitive Poetics: An Introduction. London: Routledge.

Tabakowska, E. (1993). Cognitive Linguistics and Poetics of Translation. Tübingen: Gunter Narr Verlag. 
Venuti, L. (2008). The Translator's Invisibility: A History of Translation. (2 $2^{\text {nd }}$ Ed.). London and New York: Routledge.

Wales, K. (2001). A Dictionary of Stylistics. 2nd Edition. Harlow: Longman. 